\title{
KOMUNIKASI EFEKTIF MEMBANGUN KEARIFAN DALAM DAKWAH
}

\author{
Santa Rusmalita
}

\begin{abstract}
Abstrak
"Serulah (manusia) kepada jalan Tuhanmu dengan hikmah dan pelajaran yang baik dan bantahlah mereka dengan cara yang baik. Sesungguhnya Tuhanmu Dialah yang lebih mengetahui tentang siapa yang tersesat dari jalan-Nya dan Dialah yang lebih mengetahui orang-orang yang mendapat petunjuk." (QS. An-Nahl:125)

Dakwah merupakan kegiatan mengajak manusia menuju kebahagiaan di dunia dan akhirat. Demi tercapainya tujuan kegiatan tersebut, maka diperlukan komunikasi yang sesuai dengan objek dakwah. Beragam latar objek dakwah menjadikan Da'l harus pandai-pandai memilih jenis komunikasi yang disampaikan. Ada qaulan baligha, Qaulan maisura, qaulan layyin, qaulan ma'rufa, qaulan karima dan qaulan sadiida. Setiap bentuk komunikasi tersebut memiliki makna dan titik tekan masing-masing.
\end{abstract}

Kata Kunci : Dai, komunikasi, dakwah

\section{A. Pendahuluan}

Manusia adalah makhluk sosial yang selalu berinteraksi dengan orangorang di sekitarnya. Bouman yang dikutip oleh Cholil (tt:63) mengungkapkan bahwa dalam setiap diri manusia terdapat hasrathasrat dan kecenderungankecenderungan bernaluri antara lain: (a) Kecenderungan sosial yaitu merupakan kecenderungan untuk menggabungkan dirinya dengan individu lainnya dalam bentuk kelompok. (b) Rasa harga diri yaitu harga diri yang tidak hanya tampak sebagai keinginan untuk berharga, namun juga supaya kelihatan berharga menurut pendapat orang lain.

Dalam pergaulan menurut Bouman tersebut adalah merupakan hasrat naluri manusia, sebab fitrahnya manusia hidup bersosial untuk berinteraksi. Seperti firman Allah:

Artinya: "Hai manusia, sesungguhnya Kami menciptakan kamu dari seorang laki-laki dan seorang perempuan dan menjadikan kamu berbangsa - bangsa dan bersuku-suku supaya kamu saling kenal-mengenal. Sesungguhnya orang yang paling mulia diantara kamu disisi Allah ialah orang yang paling taqwa diantara kamu. Sesungguhnya Allah Maha Mengetahui lagi Maha Mengenal." (QS. Al-Hujurat:13) 


\section{B. Dakwah untuk semua kalangan}

Secara bahasa Dakwah adalah: An-Nida (memanggil), Ad-Du'a (menyeru), Ad-Da'wat ila qadhiyat (Menegaskannya atau membelanya, baik terhadap yang hak maupun yang batil, yang positif maupun negative, Du'a (memohon dan meminta). (Jum'ah, 2010:24). Dengan memperhatikan pengertian lughawi dakwah tersebut maka dapat diketahui bahwa dakwah tujuannya adalah mengajak manusia pada surga, serta berorientasi pada akhirat.

Dakwah merupakan upaya untuk mengharmonikan hubungan manusia dengan sesama dan manusia dengan Allah (hablun minallah wa hablun minannas). Dengan memahami bahwa karakter manusia berbeda-beda, penerimaan mereka yang berbeda serta daya tangkap mereka berbeda, maka AlQuran telah memberikan arahan tentang bagaimana komunikasi menghadapi setiap orang tersebut. Menurut Hammam (2013:77), menyeru manusia harus seuai dengan kadar pemahaman mad'u. Dakwah ke jalan Allah dilandasi dengan hikmah dan nasihat yang baik. Diantara bentuk dakwah yang penuh hikmah adalah dengan mempertimbangkan kondisi dan cara yang sesuai bagi setiap orang. Sesungguhnya perkataan yang baik dalam Islam menurut Jum'ah Amin ibarat makhluk hidup yang keberadaanya mempunyai pengaruh. (2010:203)

Menurut Hammam (2013), klasifikasi mad'u dalam dakwah terbagi 3 (tiga), yaitu:

1. Orang awam yang tidak belajar, terhadap mereka berdakwah dilakukan dengan simple, tidak sulit dan pemahaman yang mendalam. Penjelasan gunakan dengan sharih (jelas).

2. Kelompok terpelajar. Kepada mereka tingkatan keilmuwan harus diperhatikan. Bisa dipaparkan sesuatu secara mendalam dan mendetail, karena mereka akan memahami apa yang kita bicarakan.

3. Orang-orang spesialis dalam bidang keilmuwan tertentu. Tiap-tiap spesialisasi mempunyai metode term sendiri. Berdakwah pada orang yang memiliki spesialisasi tersendiri adalah menyesuaikan dengan bidang mereka. Banyak orang Barat masuk Islam karena mereka mempelajari bidang mereka, dan setelah dikaitkan dengan Al-Quran, mereka mengakuinya, akhirnya mereka masuk Islam.

Ada beberapa bentuk komunikasi yang digambarkan dalam Al-Quran yang berhubungan dengan mad'u, yaitu dengan Qaulan baliigha, Qaulan 
maisuura, qaulan layyina, qaulan ma'ruufa, qaulan kariima, qaulan sadiida.

\section{a. Qaulan baligha}

Kata baligh berarti tepat, lugas, fasih, dan jelas maknanya. Qaulan Baligha artinya menggunakan kata-kata yang efektif, tepat sasaran, komunikatif, mudah dimengerti, langsung ke pokok masalah, dan tidak berbelit-belit atau bertele-tele.

Qaulan baligha dalam Al-Quran berkaitan dengan perintah Allah untuk Rasulullah agar berkata jelas (baligh) pada orang-orang munafik, agar dakwah pada mereka menjadi membekas dan dakwah pada mereka sesuai dengan apa yang telah mereka pahami.

Firman Allah:

Artinya: "Mereka itu adalah orangorang yang Allah mengetahui apa yang di dalam hati mereka. Karena itu berpalinglah kamu dari mereka, dan berilah mereka pelajaran, dan katakanlah kepada mereka perkataan yang berbekas pada jiwa mereka." (QS. An-Nisa:63)

Salim A. Fillah menjelaskan bahwa ketika perang Tabuk diserukan, waktu itu musim paceklik. Kaum Muslimin semua memanggil seruan tersebut, kecuali 3 orang, yaitu Kaab Bin Malik, Hilal bin Umayyah dan Murarah bin rabi' dan kaum munafik tentunya. Pada kesempatan ini, istri para munafik tidak mau ketinggalan, menghasud istri-istri kaum muslimin yang berangkat, dengan menakut-nakuti mereka akan kondisi yang sulit. Adapun para istri kaum muslimin tersebut menjawab: "Inna dzahaba akkal,wa baqiya arrazaq "(sesungguhnya yang pergi adalah tukang makan, sedangkan Allah yang memberikan rezeki tetap tinggal). Inilah kalimat yang membekas jiwa. Ada unsur ledekan juga bahwa para suami juga 'tukang makan', pada hakikatnya, mereka bukan pemberi rizqi \& penentu hidupmati. Begitu juga kata-kata ini sebagai sindiran bagi orang munafik, bahwa jika 'tukang makan' suami mereka (orang mukmin) pergi, maka 'tukang makan' orang-orang munafik tidak pergi dan tetap di rumah, menghabis-habiskan sediaan paceklik dan rawan, padahal mereka bukan pemberi makan, bukan pula yang menjamin keselamatan. http://www.islamedia.web.id/2012/01/kult wit-tentang-qaulan-baligha-oleh.html

Ada asas dalam qaulan baligha:

1. Qaulan balighan terjadi bila komunikator menyesuaikan pembicaraannya dengan sifat-sifat komunikan. Dalam istilah Al-Quran, ia berbicara fi anfusihim (tentang diri mereka). Dalam istilah sunah, "Berkomunikasilah kamu sesuai dengan kadar akal mereka". Pada zaman modern, ahli komunikasi berbicara tentang frame of 
reference dan field experience. Komunikator baru efektif bila ia menyesuaikan pesannya dengan kerangka rujukan dan medan pengalaman komunikannya.

2. Qaulan balighan terjadi bila komunikator menyentuh komunikan pada hati dan otaknya sekaligus. Aristoteles pernah menyebut tiga cara yang efektif untuk memengaruhi manusia, yaitu ethos, logos dan pathos. Dengan ethos (kredibilitas komunikator), kita merujuk pada kualitas komunikator. Komunikator yang jujur, dapat dipercaya, memiliki pengetahuan tinggi, akan sangat efektif untuk mempengaruhi komunikannya. Dengan logos (pendekatan rasional), kita meyakinkan orang lain tentang kebenaran argumentasi kita. Kita mengajak mereka berpikir, menggunakan akal sehat, dan membimbing sikap kritis. Kita tunjukan bahwa kita benar karena secara rasional argumentasi kita harus diterima. Dengan pathos (pendekatan emosional), kita bujuk komunikan untuk mengikuti pendapat kita. Kita getarkan emosi mereka, kita sentuh keinginan dan kerinduan mereka, kita redakan kegelisahan dan kecemasan mereka.

\section{b. Qaulan maisura}

Qaulan maisura adalah perkataan yang mudah, yaitu yang mudah dicerna oleh komunikan. Pada prinsipnya dakwah merupakan segala ucapan, tingkah laku yang berusaha untuk menjadikan mad'u agar mereka mengenal tuhannya. Secara lugas Allah menggambarkan bahwa berbicara pada golongan tertentu harus dengan qaulan maisura (perkataan yang mudah). Dalam Al-quran Allah berfirman:

Artinya: "Dan berikanlah kepada keluarga-keluarga yang dekat akan haknya, kepada orang miskin dan orang yang dalam perjalanan dan janganlah kamu menghamburhamburkan (hartamu) secara boros." (Al-Isra:26)

Artinya: "Dan jika kamu berpaling dari mereka untuk memperoleh rahmat dari Tuhanmu yang kamu harapkan, maka katakanlah kepada mereka ucapan yang pantas."(QS Al-Isra:28)

Dalam surat Al-Isra:26 di atas menyampaikan bahwa Rasulullah harus memberikan haknya pada para kerabat, orang miskin dan orang yang dalam perjalanan (musafir). Kepada merekalah Allah menyuruh untuk berbicara dengan perkataan yang mudah-mudah saja. Menurut Achmad Mubarak dalam pengantar buku Psikologi Dakwah mereka adalah masyarakat awam yang hidupnya masih disibukkan dengan kebutuhan dasar sehari-hari. (Faizah:ix) 


\section{c. Qaulan layyina}

Secara bahasa layyina artinya lemah lembut. Jadi qaulan layyina adalah perkataan yang lemah lembut. Menggunakan Perkataan yang lemah lembut disampaikan Allah pada Musa as. saat harus berdialog dengan Fir'aun. Firman Allah:

Artinya: "Maka berbicaralah kamu berdua kepadanya dengan kata-kata yang lemah lembut, mudah-mudahan ia ingat atau takut." (QS. Thaha: 44)

Karakter lawan bicara berbedabeda. Fira'un sebagai orang yang menjadi mad'u Nabi Musa adalah orang yang sangat keras dan kejam, bahkan sampai pada mengaku sebagai seorang Nabi. Nabi Musa tidak bisa sembarangan menyampaikan kebenaran padanya, karena ia juga pernah dibesarkan oleh Fir'aun. Dan sungguh indah Allah mengajarkan bahwa sebagai anak yang pernah diasuh, Nabi Musa tidak perlu keras terhadap Firaun, dan dituntun untuk menggunakan kata-kata yang lemah lembut. Dengan perkataan yang lemah lembut ini diharapkan Fir'aun menjadi tersentuh dan takut.

Ada pelajaran optimisme dari qaulan layyina. Hati manusia bukan manusia sendiri yang menggenggamnya, namun Allah yang menguasai hati manusia. Mudah saja bagi Allah untuk membukakan hati manusia yang keras sekalipun. Banyak orang yang masuk Islam karena dakwah di lakukan dengan lemah lembut. Dan fitrah manusia jika diajak komunikasi oleh orang lain, dia ingin diperlakukan dengan lemah lembut.

\section{d. Qaulan ma'rufa}

Secara harfiah Ma'ruf berarti sesuatu yang dikenal, dimengerti dan dipahami serta dapat diterima oleh masyarakat. (Asep Muhiddin, 2002:45). Perbuatan ma'ruf itu jika dikerjakan dapat diterima dan dipahami oleh manusia, dan dipuji karena begitulah yang patut dikerjakan oleh manusia yang memfungsikan akalnya sebagai ciri khas kediriannya.

Kebalikan dari kata ma'ruf adalah munkar, yakni yang dibenci, tidak disenangi, dan ditolak oleh masyarakat karena tidak patut, tidak pantas, tidak selayaknya dikerjakan oleh manusia berakal. Dalam bahasa Inggris, ma'ruf mirip dengan common sense, yakni logis dan masuk akal.

Dalam al-Quran dijelaskan:

"Dan janganlah kamu menyerahkan harta (mereka yang ada dalam kekuasaanmu) kepada orang-orang yang belum sempurna akalnya (anak yatim) yang dijadikan Allah sebagai pokok kehidupan! berilah mereka belanja dan pakaian (dari hasil harta itu) dan ucapkanlah kepada mereka kata-kata yang baik!" (QS an-Nisa: 5).

la identik dengan kata 'urf (budaya) 
yang berarti adat, dalam hal ini berarti adat yang baik. Dalam pengertiannya sebagai adat yang baik itulah (al-'urf) diakui eksistensi dan fungsinya dalam Islam, sehingga dalam teori ushul fiqh disebutkan bahwa adat dapat dijadikan sebagai hukum (al 'adah muhakkamah). Namun jika melihat dari pandangan beberapa ahli, maka ma'ruf berarti tindakan yang muncul dari dan sesaui dengan keyakinan yang benar, sedangkan munkar adalah tindakan yang tidak sesuai dengan semua perintah Allah (Asep Muhiddin, 2002:47)

Qaulan ma'rufa berarti perkataan yang sesuai dengan norma dan nilai yang berlaku di masyarakat. Selain itu, qaulan ma'rufa berarti pula perkataan yang pantas dengan latar belakang dan status seseorang. Qaulan Ma'rufa juga berkenaan dengan perkataan yang mengandung kebaikan.

Menurut Asep Muhiddin, untuk memberikan makna ma'ruf, maka dilihat dari konteksnya. Jika dilihat dari harfiahnya saja, maka akan terdengar umum dan abstrak. Untuk melihat maknanya yang spesifik, harus dilihat konteks penyebutan kata itu. Ada beberapa ayat Al-Quran tentang qaulan ma'rufa, yaitu:

1). Surat Al-BAqarah: 263

Artinya: "Perkataan yang baik dan pemberian maaf lebih baik dari sedekah yang diiringi dengan sesuatu yang menyakitkan (perasaan si penerima). Allah Maha Kaya lagi Maha Penyantun."

Ayat di atas berkaitan dengan sedekah. Ayat sebelumnya dan sesudahnya menerangkan tentang sedekah. Kata ma'ruf di atas merupakan ucapan atau perkataan. Masalah utamanya ada pada kata sadaqah. Jadi walaupun memberi adalah sesuatu yang baik, jika diringi dengan perkataan-perkataan yang menyakitkan atau menyebut-nyebut pemberian itu, hal itu mendatangkan ancaman Allah.SWT.

2). QS. An-Nisa ayat 5

Artinya: "Dan janganlah kamu serahkan kepada orang-orang yang belum sempurna akalnya harta (mereka yang ada dalam kekuasaanmu) yang dijadikan Allah sebagai pokok kehidupan. Berilah mereka belanja dan pakaian (dari hasil harta itu) dan ucapkanlah kepada mereka katakata yang baik."

3). QS. An-Nisa Ayat 8 
Artinya: "Dan apabila sewaktu pembagian itu hadir kerabat, anak yatim dan orang miskin, maka berilah mereka dari harta itu (sekedarnya) dan ucapkanlah kepada mereka perkataan yang baik."

Ini masih berkaitan dengan orang-orang yang lemah yang berada di bawah kepengurusan kita. Bahwa terhadap kerabat, anak yatim dan orang miskin, tunaikan hak-hak mereka, agar bisa menikmati harta mereka, namun jangan dilupakan untuk tetap menggunakan kata-kata yang baik dan bijak terhadap mereka.

Dalam ayat ini merupakan perintah kebaikan pada pengurus anak yatim. Jadi walaupun yang mengurus anak yatim ini sudah memberikan yang terbaik pada mereka, namun yang terpenting adalah mereka mengucapkan kata yang baik, jangan menyakiti hati mereka.

\section{e. Qaulan kariima}

Kariima artinya mulia. Qaulan Kariima artinya perkataan yang mulia, yang lemah lembut dan merendahkan diri. Qaulan Kariima khusus diperintahkan saat berhadapan dengan orangtua. Firman Allah:

Artinya: "Dan Tuhanmu telah memerintahkan supaya kamu jangan menyembah selain Dia dan hendaklah kamu berbuat baik pada ibu bapakmu dengan sebaik-baiknya. Jika salah seorang di antara keduanya atau keduaduanya sampai berumur lanjut dalam pemeliharaanmu, maka sekali-kali janganlah kamu mengatakan kepada keduanya perkataan "ah" dan janganlah kamu membentak mereka dan ucapkanlah kepada mereka perkataan yang mulia." (QS. AI-Isra:23)

Qaulan Kariima menurut Achmad Mubarok adalah perkataan yang penuh kebajikan, mudah dan lembut, tidak retorik dan tidak pula menggurui. Orangtua memiliki sensitivitas yang tinggi, karena kekuatan sudah berkurang, namun mengharapkan lebih.

Menurut Jalaluddin, orangtua pada tahap kedewasaan menengah (40-65 tahun) mencapai puncak periode usia yang paling produktif. Tetapi dalam hubungan dengan kejiwaan, pada usia ini terjadi krisis akibat pertentangan batin antara keinginan untuk bangkit dengan kemunduran diri. Karena itu umumnya pemikiran mereka tertuju pada upaya untuk kepentingan keluarga, masyarakat dan generasi mendatang. (1998:97).

Selain itu pula bahwa pada usia ini kecemasan akan penurunan fisik dan yang lainnya telah menjadi tema utama dalam deskripsi psikologis. Adapun usia 
selanjutnya, yaitu di atas usia 65 tahun manusia akan menghadapi sejumlah permasalahan. Permasalahan pertama adalah menurunnya kemampuan fisik hingga aktivitas menurun, sering mengalami gangguan kesehatan, yang menyebabkan mereka kehilangan semangat, ini juga berimbas pada perasaan mereka tidak berharga atau kurang dihargai. (Diane, 2008:733).

Melihat bahwa orangtua telah terjadi penurunan fisik dan psikisnya, maka orang-orang di sekitarnya dan kita sebagai anak harus berusaha menjaga perasaan mereka dan memuliakan mereka.

\section{f. Qaulan sadida.}

Sadida berarti jelas, jernih, terang. Achmad Mubarok menyampaikan bahwa secara umum, dakwah dilakukan dengan qaulan sadiida, yakni mengenai sasaran, benar substansinya, dan benar bahasanya. Dalam al-Quran, konteks qaulan sadida diugkapkan pada pembahasan mengenai wasiat (QS anNisa [4]: 9) dan tentang buhtan (tuduhan tanpa bukti) yang dilakukan kaum Nabi Musa kepada Nabi Musa (QS al-Ahzab [33]: 70).

Artinya: "Hai orang-orang yang beriman, janganlah kamu menjadi seperti orang-orang yang menyakiti Musa; maka Allah membersihkannya dari tuduhan-tuduhan yang mereka katakan. Dan adalah dia seorang yang mempunyai kedudukan terhormat di sisi Allah. Hai orang-orang yang beriman, bertakwalah kamu kepada Allah dan katakanlah perkataan yang benar." (QS. Al-Ahzab: 69-70)

Sebelum menjelaskan lebih jauh lagi tentang makna atau arti qaulan sadidan maka saya akan menyuguhkan atau memaparkan yang mana telah ada dalam al-qur'an yang artinya "Dan hendaklah takut kepada Allah orangorang yang seandainya meninggalkan dibelakang mereka anak-anak yang lemah, yang mereka khawatir terhadap (kesejahteraan) mereka. Oleh sebab itu hendaklah mereka bertakwa kepada Allah dan hendaklah mereka mengucapkan Qaulan Sadida yaitu perkataan yang benar" (QS. 4:9)

Qaulan Sadidan menurut pemaparan atau arti dari surat di atas yaitu suatu pembicaraan, ucapan, atau perkataan yang benar, baik dari segi substansi (materi, isi, pesan) maupun redaksi (tata bahasa).

Dari segi substansi, komunikasi Islam harus menginformasikan atau menyampaikan kebenaran, faktual, hal yang benar saja, jujur, tidak berbohong, juga tidak merekayasa atau memanipulasi fakta. 


\section{Penutup}

Seorang dai bukan manusia super, yang dapat berkomunikasi dengan semua orang tanpa hambatan dan halangan. Diperlukan kearifan untuk melakukan dakwah, yaitu kearifan sikap dan karifan komunikasi agar dakwah sampai kepada mad'u secara tepat. AlQur'an membimbing manusia agar mereka dapat berkomunikasi di semua kalangan.

Namun pada prinsipnya adalah bahwa siapapun mad'u yang kita hadapi, maka kita harus dapat berbicara dengan baik pada mereka.Selanjutnya jika ada hal-hal di luar dari keinginan seorang dai, maka serahkan saja semuanya pada Allah SWT, karena usaha sudah maksimal di lakukan.

\section{Daftar Pustaka}

Asep Muhiddin,(2002) Dakwah dalam Perspektif Al-Quran, Bandung: Pustaka Setia

Diane E. Papalia, (2008) Psikologi Perkembangan, Jakarta: Kencana, Djalaluddin,(1998) Psikologi Agama, Jakarta: Rajawali Press.

Faizah dkk (2009) Psikologi Dakwah, Jakarta: Kencana Prenada Media Group
Hammam Abdurrahim Said (2013) Qawa'iduddakwah ilallah (terj). Solo: Era Adicitra Intermedia, Jum'ah Amin Abdul Aziz (2010), Fiqh Dakwah (terj.) Solo:Era Adicitra Intermedia

M. Cholil Mansur, (tt), Sosiologi Masyarakat Kota dan Desa,Usaha Nasional: Surabaya

Munzier Suparta (2009), Metode Dakwah, Jakarta: Kencana Prenada Media Group

http://www.islamedia.web.id/2012/01/kult wit-tentang-qaulan-balighaoleh.html 